\title{
The efficacy of the fecal occult blood test in colorectal cancer screening and evaluation with the literature: Two-year follow-up results of Rize province
}

\section{Kolorektal kanser taramada uygulanan gaytada gizli kan testinin etkinliği ve literatür eşliğinde değerlendirilmesi: Rize ili iki yıllık değerlendirme}

\author{
Gökhan Demiral ${ }^{1}$, Muhammet Kadri Çolakoğlu, Remzi Adnan Akdoğan, Ahmet Pergel \\ ${ }^{1}$ Recep Tayyip Erdoğan Üniversitesi Tıp Fakültesi, Genel Cerrahi Anabilim Dalı, Rize. \\ ${ }^{2}$ Recep Tayyip Erdoğan Üniversitesi Tıp Fakültesi, Gastroenteroloji Bilim Dalı, Rize
}

Dergiye Ulaşma Tarihi:19.11.2018 Dergiye Kabul Tarihi:27.12.2018 Doi: 10.5505/aot.2019.59389

\section{ÖZET}

GİRIŞ ve AMAÇ: Kolorektal kanser (KRK)' in erken evrede tespiti mortalite ve morbidite azalmasının yanı sıra tedavi maliyetlerini de düşürmektedir. Tarama programları ile prekanseröz lezyonu veya erken evre tümörü saptamak münkündür. Bu çalışmada Rize ili Kanser Erken Teşhis Tarama ve Eğitim Merkezince KRK tarama programına alınan ve gaitada gizli kan testi (GGKT) pozitif saptanarak merkezimize yönlendirilen hastaların kolonoskopi bulguları ve klinikopatolojik verileri incelenerek tarama programının etkinliği değerlendirilmişsir.

YÖNTEM ve GEREÇLER: GGKT sonucu pozitif saptanan 144 hasta çalışmaya dahil edildi. Veriler hasta dosyalarından retrospektif olarak tarandı. Çalışma kapsamında hastaların yaş, cinsiyet gibi demografik verileri ile endoskopide saptanan bulgular, anal fizik muayene bulgusu, histopatolojik sonuçlar, GGKT pozitiflik oranı, polip + kanser saptanma oranı ve kanser saptanma oranları tespit edildi.

BULGULAR: Çalışmada hastaların 74' ü (\% 51.4) erkek, 70' i (\% 48.6) kadın ve yaş ortalaması 60.1 (min 50max 70) idi. Toplamda 109 hastada (\% 75.7) kolonoskopik bulgular normal idi. 31 hastada (\% 21.5) GGKT pozitifliğinin sebebi hemoroid/anal fissür idi. Kolonoskopisi pozitif olanlardan 21 hastada (\% 14.6) polip, 7 hastada (\% 4.9) kolon divertikülü, 5 hastada (\% 3.5) nonspesifik inflamasyon ve 2 hastada (\% 1.4) makroskopik tümör saptandı. GGKT pozitiflik oranı $\% 1.2$ (n: 144), polip + kanser saptanma oranı $\% 0.19$ (n: 23) ve kanser saptanma oran1 \% 0.017 (n: 2) idi.

TARTIŞMA ve SONUÇ: İmmünokimyasal testler modern toplum tarama programında KRK için tercih edilen seçenektir. Çalışmamızda katılımcı sayısı, test pozitifliği ve malignite tespit oranları oldukça düşük saptanmıştır. Toplumun GGKT gerekliliği konusunda bilinçlendirilerek teşvik edilmesi ve GGKT' lerin doğru uygulanması tarama programlarının başarıya ulaşmasına katkı sağlayacaktır.

Anahtar Kelimeler: Gaytada gizli kan testi, kolorektal kanser, kolonoskopi.

\begin{abstract}
INTRODUCTION: Early detection of colorectal cancer (CRC) reduces mortality and morbidity, and reduces treatment costs. It is possible to detect precancerous lesion or early stage tumor with screening programs. In this study, the efficacy of the screening program was evaluated by examining colonoscopy findings and clinicopathological data of the patients who were taken to CRC screening program by Rize province Cancer Early Diagnosis Screening and Training Center and who were referred to our clinic with positive fecal occult blood test (FOBT) result.

MATERIAL and METHODS: A total of 144 patients with positive FOBT (Wondfo One Step Fecal Occult Blood Test, Biotech Co.Ltd., Guangzhou, China) results were included in the study. Data were retrospectively reviewed from patient files. Demographic data of age and gender, endoscopic findings, anal physical examination findings, histopathological results, FOBT positivity rate, polyp + cancer detection rate and cancer detection rates were evaluated. RESULTS: In this study, 74 of the patients $(51.4 \%)$ were male and $70(48.6 \%)$ were female and the mean age was 60.1 ( $\min 50-\max 70)$. In 109 patients $(75.7 \%$ ) colonoscopic findings were normal. Hemorrhoid / anal fissure was the cause of FOBT positivity in 31 patients $(21.5 \%)$. Colonoscopy positive patients were as follows; polyp in 21 patients $(14.6 \%)$, colonic diverticulum in 7 patients ( $4.9 \%)$, nonspecific inflammation in 5 patients (3.5\%) and macroscopic tumor in 2 patients $(1.4 \%$ ). FOBT positivity rate was $1.2 \%$ (n: 144), polyp + cancer detection rate was $0.19 \%$ (n: 23 ) and cancer detection rate was $0.017 \%$ (n: 2 ).

DISCUSSION AND CONCLUSION: Immunochemical tests are the preferred choice for CRC in modern screening program. In our study; the rates of participants, test positivity and malignancy were found to be quite low. Promoting and encouraging public awareness of the need for FOBT and the correct implementation of FOBTs will contribute to the success of screening programs.
\end{abstract}


Keywords: Fecal occult blood test, colorectal cancer, colonoscopy.

\section{GİRIŞ}

Kanser ülkemizde ve dünyada ölüm nedenleri arasında ikinci sırada yer almaktadır. Kolorektal kanser (KRK)' ler ise tüm dünyada sıralamada üçüncü en sik kanserlerdir $(1,2)$. Ülkemiz Birleşik Veri Tabanı İstatistiklerine bakıldığında 2015 yılında KRK sıklığ1 erkeklerde \% 23.1 ve kadinlarda \% 14.4' dür (3). Çevresel ve genetik faktörler KRK' nin gelişme olasılığını artırmaktadır (4). En yüksek risk artışı her ne kadar genetik temelli olsa da, KRK' lerin çoğunluğunu sporadik vakalar oluşturmaktadır (5). Ailesel Adenomatozis Polipozis Koli ve Herediter Non-polipozis Kolorektal Kanser ailesel kolon kanserleri içinde en yaygın görülenler olmalarına karşılık, bunlar toplam KRK vakalarının \% 5' ten azını oluşturur (6). KRK' de erken tanı, yüksek săg kalım oranları ile ilişkili olup yapılan çalışmalar tarama ve izlemin mortaliteyi azalttığını göstermektedir $(7,8)$. KRK' nin erken evrede teşhisi mortalite ve morbidite azalmasının yanı sira tedavi maliyetlerini de düşüreceğinden asemptomatik evrede tanı imkanı sunan KRK tarama programları birçok ülkede olduğu gibi ülkemizde de uygulanmaktadır (9). Tarama programları ile prekanseröz lezyonu veya erken evre tümörü saptama olasılığı fazladır. Ülkemizde KRK tarama programı kapsamında İl Sağlık Müdürlüklerine bağl1 Kanser Erken Teşhis Tarama ve Eğitim Merkezince (KETEM) 5070 yaş aralığındaki erkek ve kadınlara 2 yılda bir gaitada gizli kan testi (GGKT) ve 10 yilda bir kolonoskopi yapılmaktadır (9).

Bu çalışmada Rize ili KETEM birimi tarafindan KRK tarama programına alınan ve GGKT pozitif saptanarak merkezimize yönlendirilen hastaların kolonoskopi bulguları ve klinikopatolojik verileri incelenerek tarama programının etkinliği değerlendirilmiştir.

\section{GEREÇ VE YÖNTEM}

KRK tarama programı kapsamında Rize İl Sağlık Müdürlügüne bağlı KETEM birimince 1 Ocak 2016 - 31 Aralı 2017 tarihleri arasinda hedef nüfus olarak belirlenen 50-70 yaş aralığında ki 73900 kişiden taramaya katılımı sağlanan 12023' üne GGKT uygulandı. Test sonucu pozitif saptanarak ilin tek referans merkezi olan hastenemize kolonoskopi amaçlı gönderilen 144 hasta çalışmaya dahil edildi. Başka hastanelerden veya kliniklerden tarama amaciyla veya GGKT pozitifliğiyle yönlendirilen hastalar bu çalışmada değerlendirilmedi. Veriler hasta dosyalarından retrospektif olarak tarandı. Eşlik eden dispeptik yakınmaları olan hastalara eş zamanlı gastroskopi uygulandi.

GGKT, verilen eğitim sonrası ücretsiz dağıtılan kit (Wondfo One Step Fecal Occult Blood Test, Biotech Co.Ltd., Guangzhou, China) ile kişi tarafından uygulandı ve testin verildiği merkeze 3 gün içerisinde geri getirilmesi sağlandı. Geri getirilmeyen kitler ile ilgili bir işlem yapılmadı ve çalışmaya alınmadı. Kasetlerin geri getirilme işlemini aile sağlığı merkezlerinde ilgili aile hekimleri, toplum sağlı̆̆ merkezlerinde ise sorumlu hekimler takip etti. GGKT' nin değerlendirilme işlemi kitleri dağıtan merkezlerdeki Sağlık Müdürlügünce eğitilmiş sağlık personelleri tarafindan yapıldı ve pozitif sonuç saptananlar hem sonuç hem de bundan sonraki süreç hakkında bilgilendirilerek gerekli yönlendirmeler yapild.

Çalışma için etik kurul onayı alındı. Endoskopik işlemler; gerekliliği ve nasıl yapılacağ1 konusunda bilgilendirme sonras1 tüm hastalardan ayrıntılı onam alınarak uygun barsak temizliğini takiben yapıldı. Tüm hastalara işlem sırasında sedasyon uygulandı. Endoskopik işlemler Genel Cerrahi ve Gastroenteroloji uzmanları tarafindan yapıldı. Gastroskopi işlemi; gerek duyulan tüm hastalarda duodenum 2. Kita ve Oddi sfinkteri görülecek biçimde; kolonoskopi işlemi ise tüm hastalarda anüsten çekum tabanına kadar tüm kolorektal bölge incelenecek biçimde uygulandi. Endoskopi esnasinda tespit edilen kitlelerden biyopsi alınarak patolojik incelemeye gönderildi. Barsak temizliği yetersiz olan 8 hastada işlem tekrarland.

Çalışma kapsamında hastaların yaş, cinsiyet gibi demografik verileri ile geçirilmiş gastointestinal sistem malignite öyküsü, endoskopide saptanan bulgular, anal fizik muayene bulgusu, biyopsi yapılan hastaların 
histopatoloji sonuçları ile operasyon gereken hastalara uygulanan cerrahi işlem sonuçları tanımlayıcı istatistiki verilere dönüştürüldü. Ayrıca GGKT pozitiflik oranı, polip + kanser saptanma oranı ve kanser saptanma oranları tespit edildi.

\section{BULGULAR}

2016 y1lında tarama hedef nüfusu 36645 olup 60031 hastaya; 2017 y1lında ise hedef nüfus 37255 olup 5992 hastaya GGKT uyguland. Çalışmada GGKT pozitif saptanan hastaların 74' ü (\% 51.4) erkek, 70' i (\% 48.6) kadın ve yaş ortalamas1 60.1 (min 50-max 70) idi. Toplamda 109 hastada (\% 75.7) kolonoskopik bulgular normal idi. 31 hastada (\% 21.5) GGKT pozitifliğinin sebebi hemoroid/anal fissür idi. Kolonoskopisi pozitif olanlardan 21 hastada (\% 14.6) polip, 7 hastada (\% 4.9) divertikül, 5 hastada (\% $\left(\begin{array}{ll}\% .5\end{array}\right)$ nonspesifik inflamasyon ve 2 hastada (\% 1.4) makroskopik tümör saptandı. Toplamda 21 hastada 27 polip saptanmış olup; hiperplastik polip 16 , tübüler adenom 7 ve tübülövillöz adenom 4 şeklinde idi. Tübülövillöz adenom saptanan hastalardan birinde intramukozal karsinom odakları içeren yüksek dereceli displazi mevcut idi. Diğer bir tübülövillöz adenomlu hastada şiddetli displazi ve tübüler adenomlu bir hastada da düşük derece displazi saptand. GGKT pozitiflik oran1 \% 1.2 (n:144), polip + kanser saptanma oran1 \% 0.19 (n:23) ve kanser saptanma oran1 $\% 0.017$ (n:2) idi.

Poliplerin tümüne polipektomi uygulandı ve sonrasında ek işleme gerek duyulmadi. Makroskopik tümör saptanan 2 hastada biyopsi sonucu adenokarsinom gelmiş olup kitle sigmoid kolon yerleşimli idi. Bu hastalarda açık yöntemle anterior rezeksiyon uç uca anastomoz işlemi uyguland1. Eş zamanlı gastroskopi yapılan hasta sayıs1 39 (\% 27) idi. Bunlar arasinda 19 hastada Helicobacter pylori pozitifliği, 18 hastada gastrit veya pangastrit, 2 hastada gastrik ülser ve 2 hastada özofajit tespit edildi. Gastroskopide malign bulgu gözlenmedi. Hastaların hiçbirinin özgeçmişinde gastrointestinal sistem malignitesi öyküsü yok idi (Tablo 1-2).

\section{TARTIŞMA}

KRK dünya genelinde erkeklerde en sik üçüncü, kadınlarda ise en sık ikinci kanser türüdür. Yaklaş1k \% 55' i gelişmiş ülkelerde görülür (10). Pek çok ülkede yaşam boyu KRK gelişme riski \% 5 civarında olup bu kişilerin yaklaşık \% 45 'i tedaviye rağmen hayatlarını kaybetmektedir (11). Tedavi yöntemlerinde son on yılda yaşanan gelişmeler ile ilerlemiş ve metastatik hastalığın seyrinde ve sağ kalımda iyileşmeler olmuştur. $\mathrm{Bu}$ gelişmelere önemli ölçüde artan tedavi maliyetleri de eşlik etmiştir. KRK erken evrede teşhis edildiğinde büyük ölçüde tedavi edilebilir bir hastalıktır. Ülkemizde yapılan çalışmalarda hastaların önemli bir kısmı ileri evrede saptanmaktadır $(12,13)$. Oysa erken teşhis ile mortalite ve morbidite azalmasinın yanı sira tedavi maliyetleri de düşecektir. Pilot çalışmalar çeşitli tarama programları ile bu maliyetlerin azaldığını göstermiştir (14). Çoğu KRK öncü lezyon olan bir adenomdan gelişir. Erken adenomun invaziv kansere doğru ilerlemesi yıllar almaktadır (15). Yüksek insidans, uzun preklinik faz, tespit ve tedavi edilebilen bir öncü lezyon varlığ 1 , yüksek tedavi maliyeti ve hastalık evresi ile ilişkili mortalite nedeniyle KRK; tarama programlarının planlanması için oldukça uygundur (16). KRK' yi erken evrede teşhis etmenin yolu asemptomatik dönemde tarama programları ile hastalığı yakalamaktır. $\mathrm{Bu}$ sayede hem kansere bağlı morbidite/mortalitenin hem de sağlı harcamalarının önemli oranda azalacağ 1 düşüncesi, KRK taramasını öneren ve uluslararası kılavuzların temelini oluşturan randomize kontrollü çalışmalar ile de desteklenmniştir (17). Bu önerilere rağmen, KRK tarama uygulaması şu anda hedef nüfusun sadece küçük bir kısmına yapılabilmektedir. Tarama programlarında gaitada gizli kan testi, sigmoidoskopi ve kolonoskopi kullanılmaktadır.

Tarama programı kapsamında yılda bir yapılan GGKT uygulamasının KRK' ye bağlı ölümleri \% 14-16, \% 22 yaşam boyu bir kez yapılan fleksible sigmoidoskopinin ise \% 27 oranında azalttı̆̆ (Tablo 3). Tarama kolonoskopisi yapılanlarda ise genel nufus ile karşılaştırıldığında \% 65 daha düşük KRK mortalitesi ve \% 67 daha düşük insidans saptanmıştır (20). Yine başka güncel vaka kontrol çalışmalarında KRK mortalitesinde \% 31 (21) ve ileri evre neoplazi saptama oranlarında \% 48 azalma bulunmuştur (22). $\mathrm{Bu}$ oranlar, tarama programlarının etkinliğini göstermektedir. $\mathrm{Bu}$ çalışmalarda

Adress for correspondence: Yard. Doç. Dr. Gökhan Demiral, Recep Tayyip Erdoğan Üniversitesi Tıp Fakültesi İslampaşa Mh 53100 Rize - Türkiye 
saptanan oranlar rektum ve sol kolon tümörleri ile sinırlı sağ kolon tümörlerinde benzer sonuçlar bulunamamıştır. Kolonoskopinin primer tarama testi olarak etkisini değerlendirmek amacıyla yapılacak geniş çaplı randomize kontrollü bir çalışma bu konuda daha net sonuçlar sunabilecektir (23).

GGKT taramasında en iyi yaş aralığına ilişkin net bir çalışma bulunmamaktadır. Bazı yazarlar 45-80 arasındaki farklı yaş aralıklarında GGKT ile mortalite azalmasının benzer olduğunu ileri sürmektedir (23). Ulusal tarama programlarında yaş aralığı; KRK insidansinın, mortalitenin ve hayat beklentisinin yüksek olduğu 60 - 64 yaş arasını mutlaka kapsamalıdır. Buradan hareketle, riskler ve faydalar gözetilerek daha genç ve daha yaşlı bireyleri içerecek şekilde yaş aralığı genişletilebilir (23). Ülkemizde KRK taramasında önerilen yaklaşım, 50-70 yaş arası tüm hastalarda iki yılda bir GGK testi ve 10 yılda bir kolonoskopi yapılmasıdır. Tarama sonlandırma yaş sınırı ise ülkemizde 70 olarak kabul edilirken, ABD' de ve Avrupa' da birçok ülkede 75 olarak kabul edilmektedir $(23,24)$. Çalışmamız da yaş ortalaması $60.1 \mathrm{idi}$.

GGKT uygulaması genel olarak guaiac (GGKTgb) yada immunokimyasal bazlı test (GGKTib)' ler ile yapilır. GGKTgb herhangi bir kanın varlığını analiz ederken, GGKTib' ler sadece insan hemoglobinine özgüdür. GGKTgb' lerin immunokimyasal testlere kıyasla analitik özellikleri ve duyarlııı̆ 1 zayıftır. Ancak maliyeti ucuz olup, kit dağıtım ve toplama sürecinde numune dayanıkl11ı ğ fazladır ve daha pratiktir. Testlerde ki pozitiflik oranları \% 2.4-6.8 arasında değişmektedir. KRK saptamada ki duyarlılık ise \% 13-50 arasındadır (Tablo 3). GGKTgb adenomlar ve kanser için zayıf - orta derecede duyarlılığa sahiptir (25). Bu nedenle tarama programlarında GGKTgb' nin her seferinde iki örneğin bulunduğu üç ardışı uygulama şeklinde yapılması önerilmekte olup tek bir test yeterli değildir (26). Bu durum katılıme1 oranını düşürür (27). GGKTgb' leri arasından daha duyarlı olan HS (Hemokult SENSA) testi önerilmektedir (28). HS' nin KRK' deki duyarl1lığ $\%$ 64-80 iken, özgüllüğü \% 87-90' dır (29). HS kullanılan 382.463 hastada yapılmış bir çalışmada test pozitiflik oranı $\%$ 4.2 bulunmuştur (30). Brenner' in tek uygulamalı GGKTgb pozitifliği sonrası 20884 hastayı kapsayan çalışmasında görülmüştür ki gaiac bazlı testlerin rutin tarama performans1 daha önce bildirilen oranlardan daha düşüktür. Rutin taramada GGKTgb ileri adenomların 9/10' unu ve KRK' nin 3/4' ünü kaçırmaktadır. Haliyle bu sonuçlar taramalarda daha etkin test kullanılması gerekliliğini ortaya koymaktadır (25).

GGKTib' ler tek bir örnekle bile adenom ve kanser için daha fazla duyarlı1ığa ve özgüllüğe sahiptir (31). $\mathrm{Bu}$ testlerin pozitiflik oranları \% $1.1-13$ arasında değişmektedir. (Tablo 3). Diğer GGKT' lerine göre daha pahalıdır ancak insan hemoglobinine özgül olduğundan diyet kisitlamas1 gerektirmez. KRK saptamada ki duyarlılığı \% 79 seviyelerinde olup (Tablo 3) yanlış pozitiflik oranı az olduğundan daha az kolonoskopi gerektiririr. Dolayısıyla maliyet etkinlikte diğerlerinin önüne geçmektedir ve toplum taraması için en uygun test seçeneği olarak kabul görmektedir. GGKTib' ler 1992 yılından beri Japonya'da toplum taramada kullanılmaktadır (32). Analitik üstünlükleri yapılan çalışmalarda da gösterilmiştir (31). Çalışmada kullanılan testlerin tümü immünkimyasal bazlı test idi.

Van Rossum ve ark.' nın 20623 kişinin davet edildiği çalışmasında toplamda 4836 GGKTgb ve 6157 GGKTib uygulanmış ve test pozitiflik oranı sirasiyla \% 2.4 (n:117) ve \% 5.5 (n:339) olarak bulunmuştur. Aynı çalışmada polip + kanser saptama oranları \% 0.8 (n:80) ve \% 2.1 (n:218); sadece kanser saptama oranları ise \% 0.1 (n:11) ve \% 0.2 (n:24) bulunmuş olup GGKTib' nin gerek polip gerekse de kanser tespiti yönünden daha üstün olduğu bildirilmiştir (31). Bir başka çalışmada Levi ve ark.' 116359 davetliden 2266' sina GGKTgb, 1224' üne GGKT ib uygulamış sırasıyla 88 (\% 3.9) ve $153(\% 12.7)$ pozitiflik saptamışlardır. Kanser + ileri adenomatöz polip oranları sırasıyla \% 1 (n:22) ve \% 2.9 (n:35); sadece kanser saptama oranlar1 \% 0.35 (n:8) ve \% 0.49 (n:6) olup immünkimyasal bazlı testlerin adenom ve kanser saptamada daha başarılı olduğunu bildirmişlerdir (33). Bizim çalışmamızda GGKT pozitiflik oranımız \% 1.2 (n:144) olup literatürün alt sınırındadır. 21 hastada polip saptanmış ve polip + kanser saptanma oranı \% 0.19 (n:23)' dur. Ayrica kanser saptama oran1 $\% 0.017$ (n:2) ile çok düşük olarak bulunmuştur. Mevcut rakamlar oldukça düşük olup ilk planda GGKT' nin her ne kadar nasil 
kullanılacağı anlatılmış olsada bireyler tarafindan yanlış uygulandığını düşündürmektedir. Kaynakların etkin ve verimli kullanılmasını sağlamak adına bu hususun üzerinde durulup eğitimlerin gerekirse video yöntem gibi metodlar ile zenginleştirilmesi ile testlerin doğru şekilde uygulanması sağlanmalıdır. Diğer yandan mevcut çalışmanın devamı sağlanarak GGKT ve kolonoskopi yapılan olgu sayısının artması ile kanser saptama oranları arasında ki ilişki takip edilmelidir.

Çalışmamızda GGK pozitifliği yapabilen malignite dişı sebepler 31 hastada (\% 21.5) hemoroid ve anal fissür; 7 hastada kolonik divertikül ve 5 hastada nonspesifik inflamasyon saptanmıştır. Saptanan bu ek hastalıkların oranı GGKT için yalancı pozitiflik sebebi olup testin özgüllüğünü etkileyen faktörlerdir. Çalışmamızda GGKT negatif olan hastaların durumu bilinmediğinden duyarlılık/özgüllük oran1 hesaplanamamıştır. Literatürde hastalara eş zamanlı gastroskopi uygulayan bir çalışma bulunmamaktadır. Çalışmamızda semptomları sebebiyle gastroskopi yapilan hastalarda malignite saptanmamış olup endoskopik ve histopatolojik bulgular eşliğinde tedavi edilmişlerdir.

Tarama programlarının tümünde görülen ortak sorunlardan biri davet edilen nüfusun büyük çoğunluğunun iştirak etmemesi ve dağıtılan testlerin dönüşlerinde eksiklikler olmasidır $(25,31)$. Tarama programının etkin olması daha fazla neoplazinin erken evrede yakalanabilmesi ile mümkün olup bunun için GGKT ve pozitiflik durumunda kolonoskopi yaptırma oranının yükseltilmesi gerekmektedir. $\mathrm{Bu}$ amaçla birinci basamak sağlık hizmeti sunumunda kanserin erken evrede saptanmasının önemi, 50-70 yaş aralığında GGKT gerekliliği ve test pozitifliği durumunda kolonoskopinin faydaları hakkında bilgilendirmeler yapilmalı ve davetler periyodik olarak tekrarlanmalıdır. Çalışmamızda 2016-2017 yılları için hedef nüfus 73900 olup bunun ancak \% 16.3 (n:12023)' üne GGKT yapılabilmiştir. KRK tarama programlarında kanser saptama oranı düşüklügünün kolonoskopi yapılma oranının düşüklüğü ile ilgili olabileceği sebebiyle kolonoskopi yapılma oranın arttırılması önerilmektedir (24). GGK pozitifliği sonras1 kolonoskopi oranları Avrupa ülkelerinde göreceli olarak yüksek olup \% 66-88 arasında seyretmektedir (24). Bizim çalışmamızda tüm GGKT pozitif hastalara kolonoskopi uygulanmış olup KETEM birimi çalışanlarının bilgilendirmesi sayesinde bunun başarıldığını düşünmekteyiz. Ancak tarama programına dahile edilen katılımcı sayısının artırılması için daha fazla gayret gösterilmesi gerekmektedir.

Etkinlikleri bilimsel çalışmalar ile ispatlanmış GGKT' ler ve endoskopik uygulamaların yanı sıra, bazı yeni teknikler KRK taraması için geliştirilme aşamasındadır. En önemlilerinden bazıları BT kolonografi (Sanal kolonoskopi), gaita veya kanda DNA ve mikroRNA incelemesi ve kapsül endoskopi taramasıdır. KRK insidansı ve mortalitesi üzerine bu yöntemlerin etkileri hakkında güncel kanıt ve standart öneriler henüz bulunmamaktadır (24). BT kolonografi hasta tercihleri açısından kolonoskopiye alternatif gözükmekle birlikte yapılan çalışmalar rutin kullanım için hazır olmadığını göstermektedir. Gaita DNA incelemesinde ise tanisal doğruluğun çok merkezli ve volümlü çalışmalar ile desteklenmesi ayrıca maliyetlerin şimdikinden çok daha az olması gerekmektedir. Diğer yandan kapsül endoskopi entübasyon, insüflasyon, ağrı ve sedasyon olmaksizın kolonoskopiye alternatif olma iddiası taşısa da tanısal doğrululuk verileri düşük bildirilmektedir (23,31). Tüm bu teknikler halihazırda tarama için uygun değildir ancak bireysel olarak kullanımları devam etmektedir. İlerleyen y1llarda bu yöntemlerle ilgili yapılan çalışmalar ışığında tarama programlarında farklı yöntemlerin uygulanması mümkün olabilir.

KETEM birimlerince GGKT pozitif saptanan tüm hastaların belirlenmiş tek merkeze yönlendirilmiş olması ve sürecin etkin takibi bu çalışmanın güçlü yanını oluşturmuştur. Hastaların tümüne kolonoskopi yapıldığından tarama programı kapsamında neoplazi tespit oranları tam olarak saptanabilmiştir. Ayrıca neoplazi dışında tespit edilen bulgular ve klinisyenin gerek duyarak gastroskopi uyguladığı hastaların verileri de değerlendirilmiştir.

İle ait verilerin düzenli olarak takip edilebildiği 2016 ve 2017 yıllarını kapsayan bu çalışmanın devam ettirilerek takip eden y1llarda katılıme sayısının artırılması sayesinde ilimizin KRK oranları hakkında faydalı bilgiler sağlanacağını düşünmekteyiz. 
Diğer yandan çalışma sayesinde elde ettiğimiz literatüre kıyasla oldukça az oranda saptanan GGKT pozitifliğinin hatalı test uygulamasına bağlı olabileceğini düşündügümüzden konuyla ilgili yapılacak eğitim faaliyetlerinin sonraki süreçte test sonuçları ve KRK saptama oranlarında artış ile neticeleneceğini ön görmekteyiz.

Bununla birlikte tarama programlarının etkinliğini ortaya koyan belirteç erken evre kanser veya adenomatöz polip saptama oranı olduğundan; çalışmamızda ki katılımcı sayısının azlığı daha fazla sayıda bireye ulaşma gerekliliğini ortaya koymuştur. $\mathrm{Bu}$ sayede ileriki yıllarda tarama etkinliği konusunda daha farklı ve literatür oranlarına yakın verilere ulaşılacağını düşünmekteyiz.

\section{SONUÇ}

Bir KRK tarama programının uygulanması stratejik kararların ele alınmasını gerektirir. Tarama yönteminin seçilmesi bu kararların temel öğesi olup immünokimyasal testler modern toplum tarama programında KRK için tercih edilen seçenek haline gelmiştir. Çalışmamızda da oldukça düşük oranda tespit etmiş olduğumuz katılımc1 sayısının artırılabilmesi için toplumun GGKT gerekliliği konusunda bilinçlendirilerek teşvik edilmesi gerekmektedir. Ayrıca katılımcıların GGKT uygulama hususunda görsel öğeler kullanılarak bilgilendirilmesi test pozitifliğini ve malignite tespit oranlarını artırarak gerekli tüm bireylere kolonoskopi yapılmasına olanak sağlayacak bu da kaynakların etkin ve verimli kullanımı ile tarama programlarının başarıya ulaşmasına katkı sağlayacaktır.

Tablo 1: Hastaların yaş, cinsiyet, hedef/taranan nüfus, gastroskopi yapilma durumu ve hemoroid/anal fissür saptanma durumunu gösteren demografik veriler.

\begin{tabular}{|c|c|c|}
\hline \multicolumn{3}{|c|}{ Demografik veriler } \\
\hline Cinsiyet & \multicolumn{2}{|c|}{$74 \mathrm{E} / 70 \mathrm{~K}$} \\
\hline Ortalama yaş (yıl) & \multicolumn{2}{|c|}{$60.1(\min 50-\max 70)$} \\
\hline \multirow[t]{3}{*}{ Hedef nüfus / Taranan nüfus } & 2016 & 2017 \\
\hline & 36645 / 6031 & $37255 / 5992$ \\
\hline & \multicolumn{2}{|c|}{$73900 / 12023(\% 16.3)$} \\
\hline GGKT pozitiflik oranı (\%) & \multicolumn{2}{|c|}{$1.2(144 / 12023)$} \\
\hline Polip + Kanser saptanma oranı (\%) & \multicolumn{2}{|c|}{$0.19(23 / 12023)$} \\
\hline Kanser saptanma oranı (\%) & \multicolumn{2}{|c|}{$0.017(2 / 12023)$} \\
\hline $\begin{array}{l}\text { GGKT pozitif hastalar arasında es } \\
\text { zamanlı gastroskopi yapılan hasta } \\
\text { sayısı }\end{array}$ & \multicolumn{2}{|c|}{$\begin{array}{l}\text { H. pylori (+) } 19 \text { hasta } \\
\text { Gastrit, pangastrit } 18 \text { hasta } \\
\text { Gastrik ülser } 2 \text { hasta } \\
\text { Özofajit } 2 \text { hasta }\end{array}$} \\
\hline
\end{tabular}

Adress for correspondence: Yard. Doç. Dr. Gökhan Demiral, Recep Tayyip Erdoğan Üniversitesi Tip Fakültesi İslampaşa Mh 53100 Rize - Türkiye e-mail: drgokhandemiral@yahoo.com

Available at www.actaoncologicaturcica.com

Copyright $(\mathcal{O}$ Ankara Onkoloji Hastanesi

\begin{tabular}{|l|l|}
\hline $\begin{array}{l}\text { GGKT pozitif hastalardan fizik } \\
\text { muayenede hemoroid / anal fissür } \\
\text { saptanan hasta sayısı }\end{array}$ & 31 (\% 21.5) \\
\hline GGKT: Gaytada gizli kan testi)
\end{tabular}

(GGKT: Gaytada gizli kan testi)

Tablo 2: Hastalara ait kolonoskopik bulgular.

\begin{tabular}{|r|c|}
\hline \multicolumn{2}{|c|}{ Kolonoskopik bulgular } \\
\hline Polip & $\begin{array}{c}21(\% \text { 14.6) hastada toplam 27 polip; } \\
\text { Hiperplastik polip: 16 } \\
\text { Tübüler adenom: } 7 \\
\text { Tübülovillöz adenom: 4 }\end{array}$ \\
\hline Kolonik divertikül & 7 (\% 4.9) \\
\hline Nonspesifik inflamasyon & $5(\%$ 3.5) \\
\hline Makroskopik tümör & $\begin{array}{c}2(\% 1.4) \\
\text { (Sigmoid kolon adenokarsinom) }\end{array}$ \\
\hline Normal kolonoskopi & $109(\%$ 75.7) \\
\hline
\end{tabular}

Tablo 3: GGKTgb ve GGKTib için test pozitiflik, KRK duyarll11k ve KRK mortalitede azalma oranlar1.

\begin{tabular}{|l|c|c|c|}
\hline & GGKTgb & GGKTib & Kolonoskopi \\
\hline $\begin{array}{l}\text { Test pozitiflik } \\
\text { oranı (\%) }\end{array}$ & $\begin{array}{c}2.4-6.8 \\
*(16)\end{array}$ & $\begin{array}{c}1.1-13 \\
*(16)\end{array}$ & - \\
\hline KRK saptamada & $13-50$ & 79 & $92-99$ \\
duyarlıl1k (\%) & $*(16)$ & $*(16)$ & $*(16)$ \\
\hline KRK mortalitede & $14-16$ & 22 & $65-68$ \\
azalma (\%) & $*(18)$ & $*(16)$ & $*(19,20)$ \\
\hline
\end{tabular}

(GGKTgb: gaiac bazlı gaytada gizli kan testi, GGKTib:

immünkimyasal bazlı gaytada gizli kan testi, KRK: Kolorektal kanser, *: Referans numarası)

\section{REFERANSLAR}

1. Cancer Fact sheet February 2018. World Health Organization. http://www.who.int/en/newsroom/fact-sheets/detail/cancer Erişim Tarihi: 05.06.2018.

2. TÜİK. Ölüm Nedeni İstatistikleri, 2015. http://www.tuik.gov.tr/PreHaberBultenleri.do?id=2 1526.

3. https://hsgm.saglik.gov.tr/depo/birimler/ kanserdb/istatistik/TurkiyeKanserIstatistikleri 2015.pdf.

4. Chan AT, Giovannucci EL. Primary prevention of colorectal cancer. Gastroenterology 2010; 38: 2029-43.

5. Wei EK, Giovannucci E, Wu K. Comparison of risk factors for colon and rectal cancer. Int $\mathbf{J}$ Cancer 2004; 108: 433-42.

6. Burt RW, DiSario JA, Cannon-Albright L. Genetics of colon cancer: impact of inheritance on colon cancer risk. Annu Rev Med 1995; 46: 371-9.

7. Tözün N, Şimşek H, Özkan H, Şimşek İ, Gören A, editörler. Kolorektal Polipler ve Polipozis Sendromları. Klinik Gastoenteroloji ve Hepatoloji. Medikal ve Nobel Yayıncılık, 2007: 963-70.

8. Dolar E. Editör. Kolorektal Tümörler. Nobel ve Güneş Yayınları. 2005: 400-8.

9. https://hsgm.saglik.gov.tr/depo/birimler/ kanserdb/yayinlar/raporlar/kolorektal.pdf.

10. GLOBOCAN. Estimated cancer incidence, mortality and prevalence worldwide in 2012. 2012. http://globocan.iarc.fr/Default.aspx 
11. Ferlay J, Shin HR, Bray F, et al. Estimates of worldwide burden of cancer in 2008: GLOBOCAN 2008. Int J Cancer 2010; 127: 2893-917.

12. Çakmur H, Anuk T, Önder T, Güven H, Köksal N. Kuzey-Doğu Anadolu Bölgesinde Görülen Kolorektal Kanserlerin Özellikleri. Turk J Colorectal Dis 2015; 25: 21-7.

13. Özkan ÖF, Kaya Ü, Güner A, Cevizci S, Özkul F, Sezer C, Reis E. Bir eğitim ve araştırma hastanesinde kolorektal kanser hastalarının demografik dağılımı ve hastalık özellikleri. Pam Tip Derg 2012; 5: 132-5.

14. Lansdorp-Vogelaar I, van Ballegooijen M, Zauber $\mathrm{AG}$, et al. Effect of rising chemotherapy costs on the cost savings of colorectal cancer screening. J Natl Cancer Inst 2009; 101: 1412-22.

15. Kuntz KM, Lansdorp-Vogelaar I, Rutter CM, et al. A systematic comparison of microsimulation models of colorectal cancer: the role of assumptions about adenoma progression. Med Decis Making $2011 ; 31: 530-9$.

16. Schreuders EH, Ruco A, Rabeneck L, et al. Colorectal cancer screening: a global overview of existing programmes. Gut 2015; 64: 1637-49.

17. Sung JJ, Ng SC, Chan FK, et al. An updated Asia Pacific Consensus Recommendations on colorectal cancer screening. Gut 2015; 64:121-32.

18. Hewitson P, Glasziou $P$, Watson $E$, et al. Cochrane systematic review of colorectal cancer screening using the fecal occult blood test (hemoccult): an update. Am J Gastroenterol 2008; 103:1541-9.

19. Bibbins-Domingo K, Grossman DC, Curry SJ, et al. Screening for Colorectal Cancer: US Preventive Services Task Force Recommendation Statement. US Preventive Services Task Force. JAMA 2016; 315: 2564-75.

20. Kahi CJ, Imperiale TF, Juliar BE, Rex DK. Effect of screening colonoscopy on colorectal cancer incidence and mortality. Clin Gastroenterol Hepatol 2009; 7: 770-5.

21. Baxter NN, Goldwasser MA, Paszat LF, Saskin R, Urbach DR, Rabeneck L. Association of colonoscopy and death from colorectal cancer. Ann Intern Med 2009; 150: 1-8.

22. Brenner H, Hoffmeister M, Arndt V, Stegmaier C, Altenhofen L, Haug U. Protection from right- and left sided colorectal neoplasms after colonoscopy: population-based study. J Natl Cancer Inst 2010; 102: 89-95.
23. Kolorektal Kanser Taraması ve Teşhisinde Avrupa Birliği Kalite Rehberi, Editorler: N. Segnan, J. Patnick, L. von Karsa, Çeviri Editörleri: Keskinkılıç B, Gültekin M, Karaca AS, Öztürk C, Hacıkamiloğlu E, Boztaş G, Turan H, Karaca M. 1. Bask1, Ankara, Ozyurt Matbaac1lık, 2014.

24. Mayir B, Ensari CB, Durhan A, Çöpelci Y. Kolorektal Kanser Tarama Amaçlı Yapılan Gaytada Gizli Kan Testi Pozitif Saptanan Hastalarda Kolonoskopi Bulguları. Turk J Colorectal Dis 2018; 28: 27-30.

25. Brenner $H$, Hoffmeister $M$, Birkner $B$, et al. Diagnostic performance of guaiac-based fecal occult blood test in routine screening: state-wide analysis from Bavaria, Germany. Am J Gastroenterol 2014; 109: 427-35.

26. Sox HC. Office-based testing for fecal occult blood: do only in case of emergency. Ann Intern Med 2005; 142: 479.

27. Nadel MR, Shapiro JA, Klabunde CN. A national survey of primary care physicians' methods for screening for fecal occult blood. Ann Intern Med 2005; 142: 86-94.

28. U.S. Preventive Services Task Force. Screening for colorectal cancer: U.S. Preventive Services Task Force recommendation statement. Ann Intern Med 2008; 149: 627-37.

29. Whitlock EP, Lin JS, Liles E. Screening for colorectal cancer: a targeted, updated systematic review for the U.S. Preventive Services Task Force. Ann Intern Med 2008; 149: 638-58.

30. Kershenbaum A, Flugelman A, Lejbkowicz F, Arad H, Rennert G. Excellent performance of Hemoccult Sensa in organised colorectal cancer screening. Eur J Cancer 2013; 49: 923-30.

31. van Rossum LG, van Rijn AF, Laheij RJ, et al. Random comparison of guaiac and immunochemical fecal occult blood tests for colorectal cancer in a screening population. Gastroenterology 2008;135: 82-90.

32. Saito H. Colorectal cancer screening using immunochemical faecal occult blood testing in Japan. J Med Screen 2006; 13: 6-7.

33. Levi $Z$, Birkenfeld $S$, Vilkin $A$, et al. A higher detection rate for colorectal cancer and advanced adenomatous polyp for screening with immunochemical fecal occult blood test than guaiac fecal occult blood test, despite lower compliance rate. A prospective, controlled, feasibility study. Int J Cancer 2011; 128: 2415-24. 